\title{
Quality of life: case study of Dhaka, Bangladesh
}

\author{
M. Mridha \\ Department of Interior Architecture and Industrial Design, \\ Swinburne University of Technology, Australia
}

\begin{abstract}
The purpose of this paper is to describe the quality of life in six major residential areas in Dhaka as part of a larger research project on residential satisfaction. The paper investigates people's feelings about life with respect to their own living standards and life experiences, including their understanding and satisfaction with housing and the neighbourhood environment. The findings indicate the holistic, socio-physical neighbourhood environment as a significant contributor to residential satisfaction for the dwellers living in developer built medium-rise apartment buildings in Dhaka. It is also evident from the findings that sociophysical features of the neighbourhood and community influence life satisfaction more than strictly physical design features of individual dwelling.

Keywords: neighbourhood, residential satisfaction, Dhaka, apartment, quality of life.
\end{abstract}

\section{Introduction}

Quality of life is the satisfaction that a person receives from surrounding human and physical conditions, which are scale-dependent and can affect the behaviour of individual people and/or groups [1]. Kahneman et al. [2] presented an overview of the literature, which addressed global evaluations of life (quality of life) and indicated that the quality of life experience is embedded in the cultural and social context of both the subject and the evaluator. An example of this statement is the work of Campbell et al. [3] whose conception of the quality of life experience (i.e. individual well-being) was operationalised in an important study that measured people's perceptions, evaluations, and satisfactions. Building on the working of Campbell et al. [3], Marans and Rodgers [4] and other researchers began to explore 
these issues from a conceptual and empirical perspective [4-7]. They found that quality of a place or geographic setting (city, neighbourhood, or dwelling) was a subjective phenomenon, and that each person occupying that setting may differ in his/her views about it. This present study is therefore examines how individual feels about his/her own standards and life experiences including his/her experience and satisfaction with housing and neighbourhood environment in the context of Dhaka, the capital city of Bangladesh.

\section{Growth of Dhaka and its urban pattern}

Dhaka is the capital and principal city of Bangladesh. Its history goes back at least four hundred years, during which it became the capital city on four instances [8].

The city has experienced a fourteen-fold increase in urban population since 1980. Researchers observed that the population of Dhaka increased with an annual growth rate of $10.78 \%$ during the period from 1974 to 1981 [9]. The current population growth of Bangladesh is $2.06 \%$, while for Dhaka it is $4.2 \%$. Its share of national urban population was $25 \%$ in $1981,31 \%$ in 1991 and $34 \%$ in 2001 respectively [10]. Consequently, Dhaka has emerged as one of the fast growing megacities of the developing countries in recent times. Compared to the enumerated population in 2001, about 1.8 million people were added, representing a 14.4 per cent increase and a 1.34 per cent average annual growth rate. No city in the world has experienced such a high growth rate in population during this period as Dhaka [11].

Dhaka has a rich background of urbanisation with various phases of cultural, social and political transformation and represents a composite form developed through the ages. However, the social as well as the spatial structure of this growing city has undergone major transformation with the changing patterns of the economic structure and the technological advancement. The inner dynamics of these changes have had a deep influence on people and their life style [12]. The social acceptance of these changes, in the formal and spatial concepts of housing demonstrates a major dependency on building developers, technology and various regulatory measures.

\section{Description of the study area}

The study was conducted in six areas of Dhaka (fig. 1) that contain the majority of medium to high density and mid to high rise housing in the city. The followings are the description of each of the area surveyed.

Dhanmondi (fig. 2) has been traditionally known as an upmarket, affluent residential area in Dhaka. Its origins can be traced back to the late 1950s when wide roads were built on a grid pattern. Vegetation was planted along roadsides and in other public places. Buildings were mostly two stories in height fostering a quiet neighbourhood environment. In response to tremendous pressure on city land in the early 1970s, the rule was relaxed and over the decades migration issues, 
aggressive real estate business policies, and increasing numbers of schools and shopping malls have transformed its quiet residential status to that of a more cosmopolitan, commercial area.

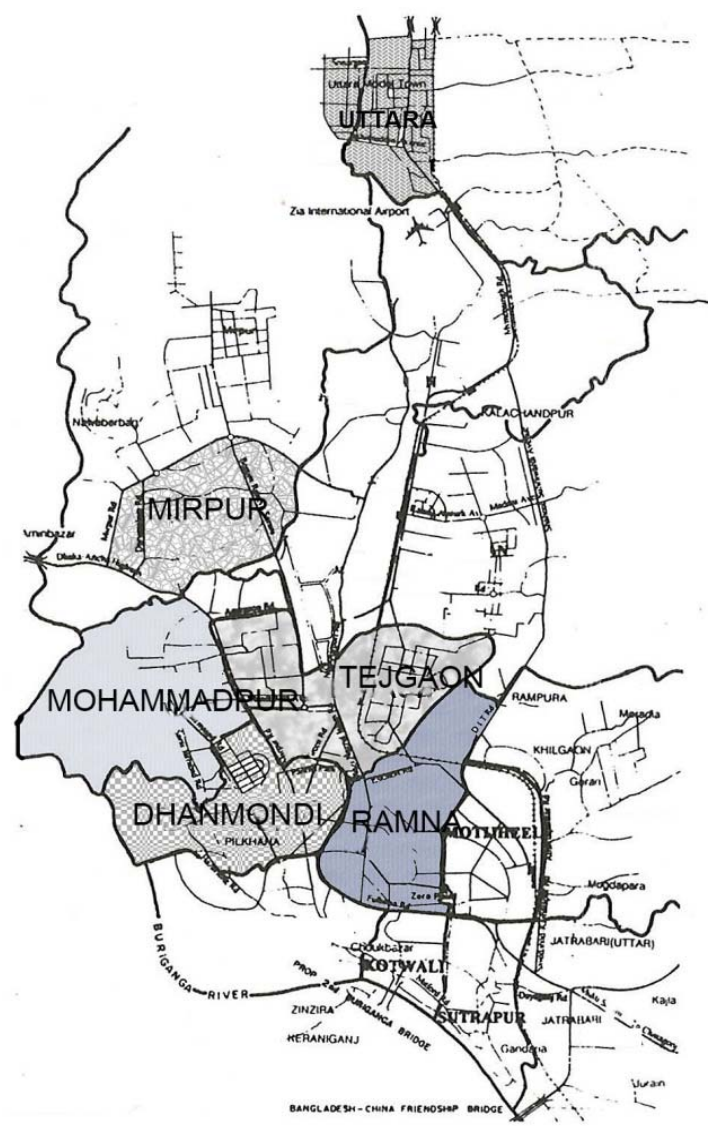

Figure 1: Location of the neighbourhoods for the study.

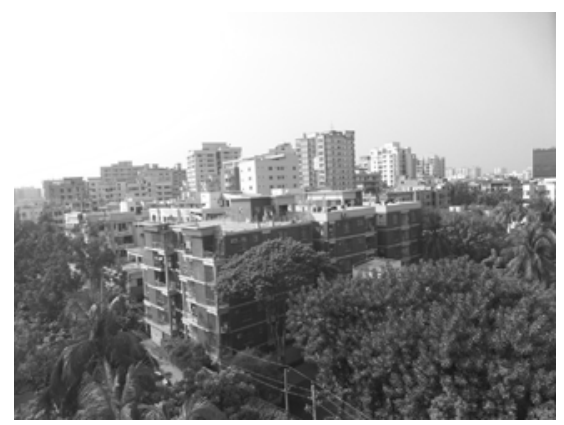

Figure 2: Dhanmondi. 
Mirpur (fig. 3) is one of the most populous areas of the Dhaka City and one of the more distant locations with respect to the city centre. However, it has well developed public transport network with other parts of the city. Mirpur gained its development momentum rapidly after 1962. Most of the land in this area is used for residential purposes followed by commercial activities. Furthermore, most of the governmental housing complexes are located here.

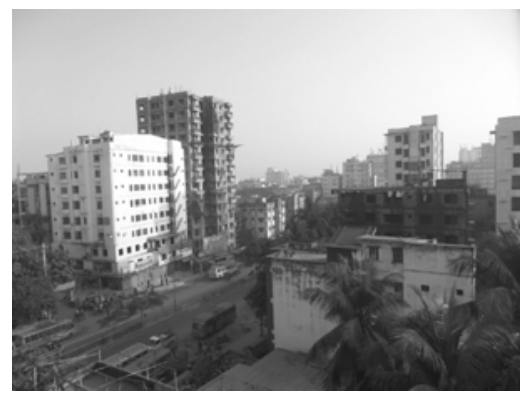

Figure 3: $\quad$ Mirpur.

Mohammadpur (fig. 4) was mainly developed as a moderate density residential area for middle-income people. Massive urbanisation has turned this area into a miniature city of apartment buildings. This has resulted in the loss of natural environment including swamps and wetlands. Most parts of Mohammadpur were planned in the 1950s with relatively broad streets and avenues. However, with the increase of population, traffic congestion in the streets and roads has increased at a faster rate. Everything is available here and the transportation system is very good with other parts of the city. This area also accommodates a number of refugee camps. These camps lack in every socio-environmental quality and have considerable negative impact on the area.

Ramna (fig. 5) is adjacent to the CBD and considered to be a very important area of Dhaka. Many government, semi-government, autonomous and private institutions are located here. Due to its location, the area experiences a very high demand for residential accommodation.

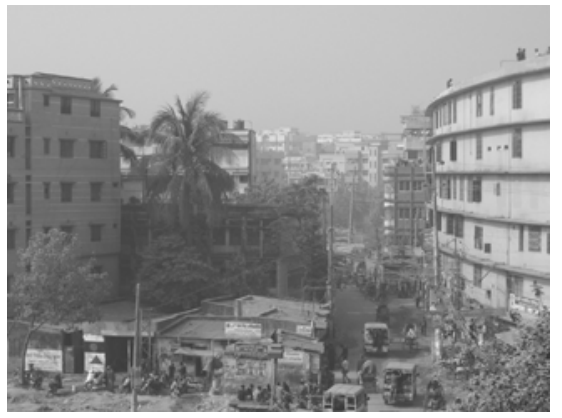

Figure 4: Mohammadpur.

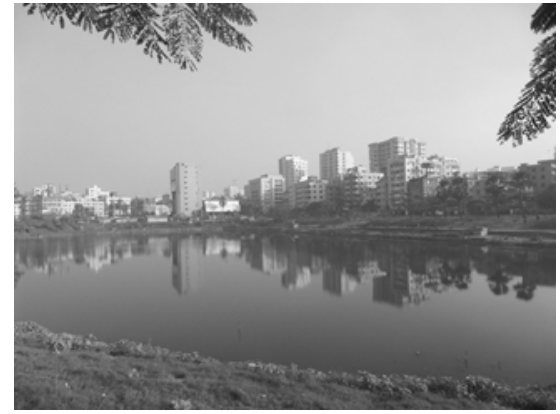

Figure 5: Ramna. 
Tejgaon (fig. 6) historically has been a centre of industrial activity in the city, which is evident by the examples of diverse industries such as garments, food processing, metal works, and pharmaceuticals etc. located in this area. Many government, semi-government and autonomous organisations and institutions are also situated in this area. Almost every bank operating in Bangladesh has a branch in Tejgaon. Being near the city centre and close to all civic facilities, Tejgaon has emerged as an important business district of Dhaka and gradually been transformed to a very densely populated area.

Uttara (fig. 7) is primarily a residential suburb. The majority of the residents are from upper- and higher-middle-class backgrounds who prefer to live some distance from the congestion and pollution of the city. Well into the 1990s, Uttara retained its quiet, leafy suburban character. However, in recent years, with the increasing influx of people moving in from the city, Uttara has evolved into a busy town, similar to other areas of Dhaka. The suburb is well served by a proliferation of shopping complexes, government and private institutions and organisations. Being in close proximity to the international airport, Uttara has a many hotels and bed-and-breakfasts as well.

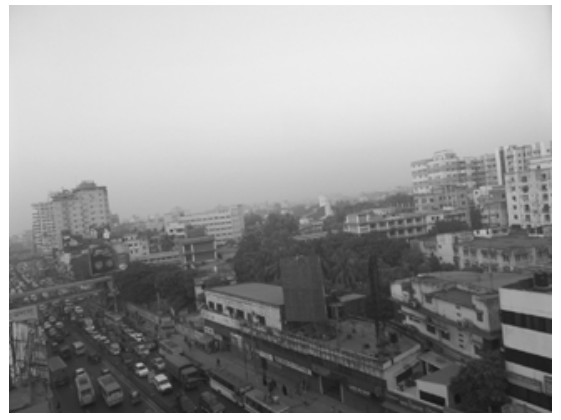

Figure 6: Tejgaon.

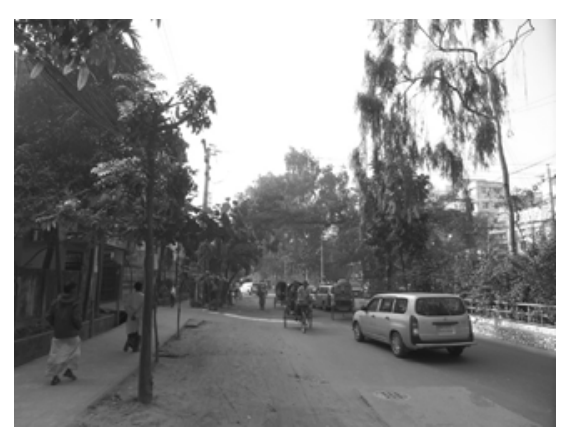

Figure 7: Uttara.

\section{The scenario}

Neighbourhood as a physical setting is critical for human well-being. Neighbourhoods are ideal units to study and assess quality of life as they combine physical and social aspects that impact on daily life [13].

This study investigates quality of life in some selected neighbourhoods in Dhaka as a part of larger research project and considers quality of life as an important focus while taking into account the interaction between man and their urban environment. The quality of the urban environment as a living space for the peoples of the world has emerged as an issue of fundamental concern for academic researchers, policy makers and citizens [14]. However, there is very little research done on quality of life in Dhaka. Izutsua et al. [15] conducted a study aims to clarify the quality of life, mental health, and nutritional status of adolescents in 
Dhaka city. Few studies were conducted on quality of life of elder people in rural areas [16-18] and quality of life of workers [19, 20] but no study has been conducted on urban quality of life. Therefore, studies are essential to understand quality of environment that are preferred and perceived as satisfactory urban quality of life by the inhabitants living in various neighbourhoods in Dhaka.

\section{Method}

The basic research design used for this study is survey research. The study surveyed respondents using a pilot-studied, structured questionnaire in two stages. First, pilot studies were conducted in a Bangladeshi community in Sydney and later in Dhaka to develop and test the research instrument. Second, using the refined instrument, the main study was conducted in Dhaka households with the purpose of addressing the research questions.

\subsection{The sample}

A representative sample of Dhaka households was selected using a stratified random sampling approach. To ensure a representative and random sample of the population living in mid- to high-rise housing, several steps were taken. First, six areas of the city with the majority of medium- to high-density, mid- to high-rise housing were selected (see fig. 1). Second, a subset of buildings was chosen randomly from within each area. Third, sub-populations were selected based on floor levels (two upper floors versus two lower floors of each building). Fourth, from among the upper and lower floors, apartment units were then randomly selected. Finally, one adult respondent 18 years of age or older was selected at the time of the interview in the sampled units.

The sample size was based on established sampling criteria. A sample size of at least 200 respondents was required according to tables in de Vaus [21] in order to achieve no more than a $7 \%$ sampling error with $95 \%$ confidence level assuming a 50/50 split. In anticipation of non-responses, 236 people were contacted to obtain the final sample of 204 interviews.

\subsection{Measurement instrument}

A structured questionnaire was developed to measure resident perceptions and evaluations about a number of aspects of their housing and neighbourhood environment. Each question was measured on a linear numeric version of a Likerttype scale " 1 " standing for strong level of dissatisfaction and " 5 " representing a strong level of satisfaction. To give more options to respondents and to achieve precision consistent with reliability, questions about overall satisfaction were added at the end of each section on a seven-point linear numeric scale. As the primary language of the respondents was Bangla, the questionnaire was translated into Bangla. 


\section{Results}

The survey data were analysed using a number of statistical tool to identify quality of life by considering satisfaction with the neighbourhood in Dhaka. The following summarises the major results regarding the components of residential satisfaction.

\subsection{Neighbourhood quality is a major component of residential satisfaction}

All continuous variables used to measure residential satisfaction were examined through factor analysis in order to identify the components of residential satisfaction. Principal component analysis revealed six components of residential satisfaction as 'Management and maintenance', 'Architectural features', 'Neighbourhoods', 'Neighbours', 'Recreation facilities', and 'Ambient environment'. Among them Neighbourhood, Neighbours, and Recreation facilities, relate to the socio-physical quality of neighbourhood. They clearly indicate the importance of the socio-physical neighbourhood environment as a major contributor to residential satisfaction in medium- to high-rise apartment living in Dhaka.

Neighbourhood as a component comprised ten items of residential satisfaction (Table 1). The factor loading of each of these ten items was higher than on the other five components of residential satisfaction. Overall, all the items relate to the quality of Neighbourhood. Eigenvalue of this component was 3.85 and accounted for $6 \%$ of the total variance in residential satisfaction across the 204 respondents. Correlation values of the items were very strong, ranging from 0.227 to 0.629 , while the reliability coefficient $(0.869)$ indicated strong internal consistency of this item set.

Table 1: Factor analysis result of the component 'Neighbourhood'.

\begin{tabular}{|l|c|}
\hline Item description & Factor loading \\
\hline Neighbourhood cleanliness & 0.81 \\
\hline Traffic safety & 0.79 \\
\hline Neighbourhood parking facilities & 0.74 \\
\hline Noise level as created by traffic & 0.71 \\
\hline Street condition in the neighbourhood & 0.66 \\
\hline Crime and vandalism situation & 0.65 \\
\hline Garbage disposal of neighbourhood & 0.59 \\
\hline Open space condition in the neighbourhood & 0.52 \\
\hline Physical appearance of neighbourhood buildings & 0.49 \\
\hline Neighbourhood building maintenance & 0.46 \\
\hline
\end{tabular}

\subsection{The neighbourhood and overall residential satisfaction}

Multiple regression analysis was employed to examine how well the components of residential satisfaction predicted overall residential satisfaction. According to Table 2, Neighbourhood had the second largest beta coefficient (0.28), indicating that this component was not only the second factor extracted after Management 
and maintenance but also the second strongest contribution to overall residential satisfaction. Taken together with the factor of Recreation facilities (which included satisfaction with parks, playing fields, libraries and other neighbourhood facilities), these results clearly indicate the importance of the neighbourhood environment as a major component of residential satisfaction in medium- to highrise apartment living in Dhaka.

Table 2: Coefficients of the components of residential satisfaction.

\begin{tabular}{|l|l|l|}
\hline \multirow{2}{*}{ Component } & $\begin{array}{l}\text { Standardised } \\
\text { coefficients }\end{array}$ & Sig. \\
\cline { 2 - 3 } & Beta & \\
\hline Management and maintenance & 0.48 & 0.001 \\
\hline Neighbourhood & 0.28 & 0.001 \\
\hline Architectural features & 0.22 & 0.001 \\
\hline Neighbours & -0.19 & 0.001 \\
\hline Ambient environment & -0.14 & 0.001 \\
\hline Recreation facilities & 0.08 & 0.05 \\
\hline
\end{tabular}

It was of interest to determine if there were differences in levels of reported satisfaction between neighbourhoods. Therefore, a further analysis was performed with respect to the location of neighbourhoods. Fig. 8 shows these differences in terms of percentage of satisfied and dissatisfied residents. The figure suggests that percentages of satisfied residents were highest in Uttara and Tejgaon and lowest in Mirpur and Mohammadpur. 65\% of the respondents in Uttara were satisfied with "living here" as compared to only $17 \%$ in Mohammadpur. Taking Uttara and Mohammadpur as extreme cases, an ANOVA with planned comparisons was performed to investigate whether or not there was a statistically significant difference between these two locations and extremes of satisfaction. Table 3 (second row) indicates that the contrast is highly significant at the $\mathrm{p} \leq 0.001$ level. Therefore, it can be concluded that there is a statistically significant difference the perception of satisfaction between residents living in Uttara and Mohammadpur.

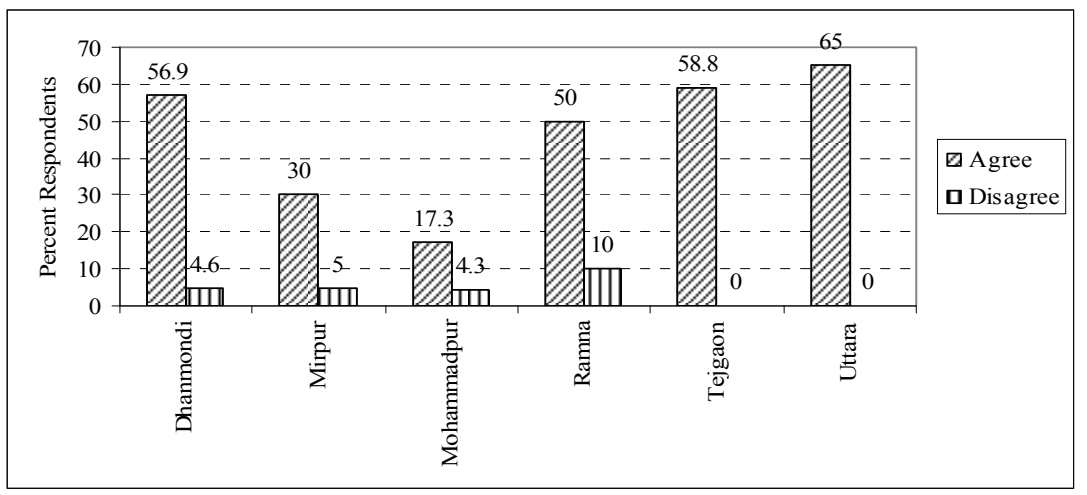

Figure 8: Percentage of agreement or disagreement of satisfaction with 'living here' by location. 
Table 3: Contrast test between Uttara and Mohammadpur for comparison of 'overall satisfaction in living here'.

\begin{tabular}{|l|l|c|c|c|c|c|c|}
\hline \multicolumn{2}{|c|}{} & Contrast & $\begin{array}{c}\text { Value of } \\
\text { contrast }\end{array}$ & $\begin{array}{c}\text { Std. } \\
\text { error }\end{array}$ & $\mathrm{t}$ & $\mathrm{de}$ & $\begin{array}{c}\text { Sig } \\
(2 \text {-tailed })\end{array}$ \\
\hline $\begin{array}{l}\text { Overall } \\
\text { satisfaction }\end{array}$ & $\begin{array}{l}\text { Assume equal } \\
\text { variances }\end{array}$ & 1 & 1.43 & .37 & $\begin{array}{c}3.8 \\
6\end{array}$ & 199 & .001 \\
\cline { 2 - 8 } & $\begin{array}{l}\text { Do not assume } \\
\text { equal variances }\end{array}$ & 1 & 1.43 & .29 & $\begin{array}{c}4.8 \\
4\end{array}$ & $\begin{array}{c}43.5 \\
2\end{array}$ & .001 \\
\hline
\end{tabular}

\section{Discussion}

Neighbourhood refers to the physical setting, activities, and boundaries, where the communal life to refers the norms, values and common beliefs of a group of people affecting quality of life.

Neighbourhood satisfaction is considered as one of the most frequently researched topics in neighbourhood studies [22] and a typical component of residential satisfaction studies. High neighbourhood satisfaction has been found to increase households' sense of community and vice versa [23, 24]. Oktay and Rustemli [25] investigated the quality of life in order to understand how people felt about their neighbourhood while neighbourhood was an important component of Turkoglu et al.'s [26] study to measure quality of urban life in Istanbul.

Studies by both Salleh [27] and by Husna and Nurizan [28] found that neighbourhood factors influence residents' needs and expectations and were very important in determining residential satisfaction. These findings have been confirmed in the current study conducted in Dhaka. The micro and macro neighbourhood defined as respondent's immediate surroundings and larger overall neighbourhood respectively, both have been found critical to residential satisfaction in Dhaka. For example, regarding microneighbourhood, questions were asked about physical appearance of neighbourhood buildings, street condition, building maintenance, noise, parking, traffic and garbage disposal. At the macro-neighbourhood level consideration was given to open space, children and adult recreation facility, neighbourhood cleanliness, crime and vandalism and overall satisfaction.

\subsection{Micro-macro relationship}

Clean neighbourhood was one of the prime concerns of respondents for satisfaction. However, the majority of them were dissatisfied with the quality of cleanliness of their neighbourhood. Respondents were not happy with parking facilities in the neighbourhood, were bothered by the noise generated by traffic and were dissatisfied with the quality of building maintenance. There is also a lack of open parkland for recreation indicating the necessity for a more sympathetic approach to improve this situation in the present urbanisation process in Dhaka.

There are moderate correlations between overall satisfaction in living 'here' with traffic safety and the street condition of the neighbourhood. It emphasises the fact that safety issues associated with a location are significant in predicting 
satisfaction. Since the overall crime and vandalism rates are low within the studied neighbourhood, the only safety concern was with traffic conditions. An improved street condition (e.g. adequate lighting, signage, maintenance) would improve safety on the street for the residents living in these neighbourhoods.

There is also very high correlation between neighbourhood cleanliness and garbage disposal $(r=0.629)$. It establishes that proper, effective and regular garbage disposal makes a neighbourhood clean, which is very important in the perceptions of respondents.

A growing proportion of people in Dhaka have access to and ability to pay for housing of reasonable quality. It appears, therefore, that other aspects of the residential environment have become more important to overall residential satisfaction, namely the perception and evaluation of their neighbourhood. For instance, as found in this study, people are more concerned about neighbourhood cleanliness and traffic safety and about the presence of children's and adult recreation facilities, as well as the condition of surrounding streets and open space in the neighbourhood, than about the physical appearance of their own apartment building or layout of their own apartment unit.

\subsection{Locational factor (Uttara vs. Mohammadpur)}

Location of the neighbourhood in the larger urban conglomeration plays an important role on residential satisfaction. Studies of Burby and Weiss [29], Michelson [30], Francescato et al. [31], Chi and Griffin [32] all indicate that location of the neighbourhood plays a significant role determining families move or settlement decision.

In the present study, the greatest difference in residents' expectations was between the two neighbourhoods of Mohammadpur and Uttara. The majority of the residents in the former were dissatisfied while those in the latter were satisfied. What makes them different? Table 4 indicates that although a high percentage of residents of Mohammadpur were satisfied with safety and security issues, however, these items were not strong predictors of satisfaction. Respondents were less satisfied with the physical appearance of neighbourhood buildings, building maintenance, open space conditions, and cleanliness. These items appeared to be the main source of dissatisfaction. Earlier literature supports the concept that appearance is a predictor of residential satisfaction [31]. The majority of the residents of Uttara expressed satisfaction with the physical appearance, safety and security, and street conditions in their neighbourhood. These were dominant predictors of satisfaction. In both locations, the fact that people were dissatisfied with recreational facilities was not a strong influence on their overall satisfaction.

\section{Conclusion}

Neighbourhood is primarily a social phenomenon arising from cohabitation in a physical area. Affiliation and bonding of community members with one another within a neighbourhood is important and a way of acquiring identity. The 
Table 4: Comparative assessment of neighbourhood by respondents.

\begin{tabular}{|l|c|c|c|c|}
\hline \multirow{2}{*}{} & \multicolumn{2}{|c|}{ Mohammadpur } & \multicolumn{2}{c|}{ Uttara } \\
\cline { 2 - 5 } & Satisfied (\%) & Dissatisfied (\%) & Satisfied (\%) & Dissatisfied (\%) \\
\hline $\begin{array}{l}\text { Physical appearance of the } \\
\text { neighbourhood buildings }\end{array}$ & 13.0 & 39.1 & 70.0 & 15.0 \\
\hline Open space & 17.4 & 43.5 & 42.5 & 27.5 \\
\hline Street condition & 21.7 & 39.1 & 57.5 & 12.5 \\
\hline $\begin{array}{l}\text { Children's recreation } \\
\text { facilities }\end{array}$ & 13.0 & 65.2 & 27.5 & 50.0 \\
\hline Adult recreation facilities & 13.0 & 65.2 & 5.0 & 55.0 \\
\hline Building maintenance & 4.3 & 56.5 & 42.5 & 15.0 \\
\hline $\begin{array}{l}\text { Noise level as created by } \\
\text { traffic }\end{array}$ & 43.4 & 39.1 & 50.0 & 25.0 \\
\hline $\begin{array}{l}\text { Neighbourhood parking } \\
\text { facilities }\end{array}$ & 39.1 & 30.4 & 50.0 & 15.0 \\
\hline Neighbourhood cleanliness & 17.3 & 60.9 & 50.0 & 15.0 \\
\hline Traffic safety & 30.4 & 26.1 & 60.0 & 10.0 \\
\hline Crime and vandalism & 56.5 & 8.7 & 75.0 & 15.0 \\
\hline Garbage disposal & 43.4 & 26.1 & 67.5 & 12.5 \\
\hline $\begin{array}{l}\text { Overall satisfaction with } \\
\text { neighbourhood }\end{array}$ & 8.7 & - & 50.0 & 2.5 \\
\hline
\end{tabular}

importance of neighbourhood is very high as it is the basic environmental unit in which social life occurs, Therefore can affect residents' overall quality of life. High neighbourhood satisfaction contributes to strong sense of community while low satisfaction influences their decision to move elsewhere.

The physical quality of the neighbourhood is a dominant predicator of overall residential satisfaction as revealed from the factor and regression analyses. This finding reflects similar findings as research conducted in various parts of the world on residential satisfaction that neighbourhood quality is critical in residential satisfaction. This finding is supported by two other factors - neighbours and recreation facilities found in this study.

The current study also found that the social, economic, and physical environments all contribute to the quality of urban life. How do they work? The answer is through the mediating effects of neighbourhood and community on residential satisfaction and thus onto overall quality of life. In particular, satisfaction with the physical environment of the neighbourhood, neighbours, and neighbourhood social life affects life satisfaction through what we might call community satisfaction. These overall feelings about the community can play a significant role in life satisfaction.

In conclusion, the study highlights the facts that the overall socio-physical features of the neighbourhood and community influence life satisfaction more than the physical features of the individual dwelling in Dhaka. 


\section{References}

[1] Mulligan, G., Carruthers, J. \& Cahil, M., Urban quality of life and public policy: A survey. Advances in urban economics, ed. R. Capello \& P. Nijkamp, Elsevier Science B: Amsterdam, pp. 729-802, 2004.

[2] Kahneman, D., Deiner, D. \& Schwarz, N., (eds). Well-Being: The Foundations of Hedonic Psychology. Russell Sage Foundation: New York, 1999.

[3] Campbell, A., Converse, P. E. \& Rodgers, W. L., The quality of American life: Perceptions, evaluations, and satisfactions, New York: Russell Sage Foundation, 1976.

[4] Marans, R. \& Rodgers, W. L., Toward an understanding of community satisfaction. Metropolitan America in contemporary perspective, ed. A. H. Hawley \& V. P. Rock, Wiley: New York, pp. 299-352, 1975.

[5] Lee, T. \& Marans, R. W., Objective and subjective indicators: scale discordance on interrelationships, Social Indicators Research, 6, pp. 47-64, 1980.

[6] Connerly, C. \& Marans, R. W., Comparing global measures of perceived neighborhood quality, Social Indicators Research, pp. 29-47, 1985.

[7] Connerly, C. \& Marans, R. W., Neighborhood quality: A description and analysis of indicators. The US Handbook on Housing and the Built Environment, ed. E. Huttman \& W. van Vliet, Greenwood Press: Westwood, CO., 1988.

[8] Hossain, S., Echoes from old Dhaka, Dhaka, Bangladesh: Hakkanni, 1990.

[9] UNDP 1994 report on human development in Bangladesh: Empowerment of women. Dhaka, Bangladesh: United Nations Development Programme (UNDP), 1994.

[10] Mohiuddin, M., The Real Estate Business in Dhaka City: Growth and Contribution to the Economy of Bangladesh, Journal of Business and Management, 16(4), pp. 58-60, 2014.

[11] Shams, M., Shohel, M. M. C. \& Ahsan, A., Housing Problems for Middle and Low Income People in Bangladesh: Challenges of Dhaka Megacity, Environment and Urbanization Asia, 5(1), pp. 175-184, 2014.

[12] Mridha, A. M. M. H. \& Moore, G. T., The quality of life in Dhaka, Bangladesh: Neighborhood quality as a major component of residential satisfaction. Investigating Quality of Life, eds. R. W. Marans \& R. J. Stimson, Springer: Dordrecht, Heidelberg, London, New York, pp. 251272, 2011.

[13] Romice, O., Neighbourhood quality of life-Global and local trends, attitudes and skills for development. Housing, space and quality of life, eds. R. García-Mira, D. L. Uzzell, E. Real \& J. Romay, Ashgte: Aldershot, England, pp. 71-79, 2005.

[14] Das, D., Urban Quality of Life: A Case Study of Guwahati, Social Indicators Research, 88, pp. 297-310, 2008.

[15] Izutsua, T., Tsutsumi, A., Islam, A. M., Kato, S., Wakai, S. \& Kurita, H., Mental health, quality of life, and nutritional status of adolescents in Dhaka, 
Bangladesh: Comparison between an urban slum and a non-slum area, Social Science \& Medicine, 63, pp. 1477-1488, 2006.

[16] Nilsson, J., Grafström, M., Zaman, S. \& Kabir, Z. N., Role and function: Aspects of quality of life of older people in rural Bangladesh, Journal of Aging Studies, 19(3), pp. 363-374, 2005.

[17] Nilsson, J., Rana, A. K. M. M. \& Kabir, Z. N., Social Capital and Quality of Life in Old Age, Journal of Aging and Health, 18(3), pp. 419-434, 2006.

[18] Rana, A. K. M. M., Wahlin, A., Lundborg, C. S. \& Kabir, Z. N., Impact of health education on health-related quality of life among elderly persons: results from a community-based intervention study in rural Bangladesh, Health Promotion International, 24(1), pp. 36-45, 2009.

[19] Khaleque, A., Industrial pollution and quality of life of workers in Bangladesh, Journal of Human Ergology, 24(1), pp. 13-23, 1995.

[20] Khaleque, A., Sleep Deficiency and Quality of Life of Shift Workers, Social Indicators Research, 46(2), pp. 181-189, 1999.

[21] de Vaus, D. A., Surveys in social research (5th ed.), Crows Nest, NSW, Australia: Allen \& Unwin, 2002.

[22] Hur, M. \& Morrow-Jones, H., Factors That Influence Residents' Satisfaction with Neighborhoods, Environment and Behavior, 40(5), pp. 619-635, 2008.

[23] Brower, S., Designing for community, College Park: University of Maryland Press, 2003.

[24] Mesch, G. S. \& Manor, O., Social ties, environmental perception, and local attachment, Environment and Behavior, 30(4), pp. 504-519, 1998.

[25] Oktay, D. \& Rustemli, A., The Quality of Urban life and Neighbourhood Satisfaction in Famagusta, Northern Cyprus. Investigating Quality of Life, eds. R. W. Marans \& R. J. Stimson, Springer: Dordrecht, Heidelberg, London, New York, pp. 233-249, 2011.

[26] Turkoglu, H., Bolen, F., Baran, P. K. \& Terzi, F., Measuring Quality of life in Istanbul. Investigating Quality of Life, eds. R. W. Marans \& R. J. Stimson, Springer: Dordrecht, Heidelberg, London, New York, pp. 209-231, 2011.

[27] Salleh, A. G., Neighbourhood factors in private low-cost housing in Malaysia, Habitat International, 32(4), pp. 485-493, 2008.

[28] Husna, S. \& Nurizan, Y., Housing provision and satisfaction of low-income households in Kuala Lumpur, Habitat International, 11(4), pp. 27-38, 1987.

[29] Burby, R. J., III, \& Weiss, S. F., New Communities USA, Lexington, Mass.: Lexington Books, 1976.

[30] Michelson, W., Environmental Choice, Human Behavior, and Residential Satisfaction, New York: Oxford University Press, 1977.

[31] Francescato, G., Weidemann, S., Anderson, J. R. \& Chenoweth, R. E., Residents' satisfaction in HUD-assisted housing: Design and management factors. Washington, DC: US Department of Housing and Urban Development, 1979.

[32] Chi, P. S. K. \& Griffin, M. D., Social Indicators for Measuring Residential satisfaction in Marginal Settlements in Costa Rica, Social Indicators Research, 8(4), pp. 453-465, 1980. 